\title{
Uncertainty Analysis of Flow Resistance Modeling In Sewer Pipes With Different Bed Conditions Using KELM Method
}

\author{
Roghaye Ghasempour \\ University of Tabriz \\ Kiyoumars Roushangar \\ University of Tabriz \\ Hazi Mohammad Azamathulla \\ University of the West Indies St. Augustine \\ Farhad Alizadeh ( $\square$ f.alizadeh.ce@gmail.com ) \\ University of Tabriz https://orcid.org/0000-0003-1986-7424
}

\section{Research Article}

Keywords: Circular channels, Factorial Analysis, Flow resistance, Intelligence methods, Channel roughness

Posted Date: January 27th, 2022

DOI: https://doi.org/10.21203/rs.3.rs-1191432/v1

License: (c) (i) This work is licensed under a Creative Commons Attribution 4.0 International License. Read Full License 


\section{Abstract}

An accurate prediction of flow resistance in channels or pipes which is used for carrying rain water or sewage is an important issue in hydraulic engineering. In this study, the capability of two artificial intelligence methods namely; Feed Forward Neural Network (FFNN) and Kernel Extreme Learning Machine (KELM) was utilized for the Manning roughness coefficient modeling in circular sewer pipes with smooth and rough beds. During model developing process, at first the most effective variables related to hydraulic and sediment properties were selected using Factorial Analysis (FA) method, then, various models were developed based on the selected parameters. The models were tested using some available experimental datasets. The obtained results showed that there resulted high efficiency with FFNN and KELM methods in Manning coefficient modeling. It was found that both hydraulic and sediment properties were effective in modeling process. The sensitivity analysis results showed that $d_{50} / R$ variable (the ratio of median diameter of sediment size to the hydraulic radius) was the most significant parameter in modeling process. Finally, an uncertainty analysis was conducted to assess the dependability of the best applied model, and the results revealed that the KELM model possesses an acceptable level of uncertainty in roughness coefficient modeling.

\section{Highlights}

- FFNN, KELM methods were selected to identify influential parameters for prediction of roughness coefficient in circular sewer pipes

- Experimental datasets were used to feed the utilized models

- Uncertainty analysis was done to evaluate the best-applied model dependability

- Results showed an allowable degree of uncertainty in roughness coefficient modeling using the applied models

\section{Introduction}

Precise prediction of roughness coefficient is of utmost importance in circular channels such as sewer pipes, which are used for carrying rain water and sewage. Sewer system is one of the essential hydraulic structures. The presence of sediment always influences the movement of waste water in sewer pipe and also reduces the capacity of the pipes with its deposition. Reduced ability of sediment movement in sewer pipes sometime causes surcharging, blockage, and overflow of sewage water. Therefore, exact information of roughness coefficient is necessary for the design and proper functioning of sewer system. In sewer system exact information of roughness coefficient of pipes depends on several factors like bed forms and bed material etc. In the past few decades several researchers investigated the phenomena of flow resistance in open and closed channels [MeyerPeter and Mueller (1948); Einstein and Barbarossa (1952); Ackers (1961); Richardson and Simons (1967); Henderson (1984); Ashley et al. (1992); Yang et al. (2005); and Van der Mark et al. (2008)] and a large number of conventional models has been proposed for the flow resistance in channels but these models were very complex. May (1989) investigated the limit of sediment deposition in pipe and this investigations were carried out on 77 and $158 \mathrm{~mm}$ diameter smooth pipes and flow conditions, which were full or partially full. Ackers et al. (1964) found presence of permanent deposition of sediments in utilized sewer pipes. Nalluri and Ota (2000) developed a model for estimation of sediment transport capacity at the highest limit of deposition. But these models do not provide satisfactory results with the larger channels. Thus, Ota and Nalluri (2003) made an extension of their previous work and developed a model for the estimation of sediment transport in large diameter channels. Henderson (1984) has investigated the performance of sewer system and suggested the sewer roughness has a vital role in the performance of sewer system capacity. Sewer hydraulic roughness is affected by various factors: sewer material, connections of pipes, sliming and existence of sediment deposits. Novak and Nalluri (1972) investigated the channel roughness. Ojos (1978) extended the work of Novak and Nalluri (1972) by using $305 \mathrm{~mm}$ broad rectangular channel for measuring the effects of particle groupings, spacing and roughness of the channels. Kleijwegt (1992) carried out experiments on $152 \mathrm{~mm}$ diameter pipes running fully and partial fully. Also, May (2003) carried out experiments using horizontal pipe for studying sediment transport capacity and roughness coefficient of pipes and proposed a new design method. However, the outcomes of conventional models are not generalised due to the roughness coefficient complexity and uncertainty. Therefore, it is necessary to adopt or develop new methods for the accurate estimation of roughness coefficient in pipes considering different hydraulic or bed conditions.

Recently, Artificial intelligence (Al) methods [e.g., Artificial Neural Networks (ANNs), Neuro-Fuzzy models (NF), Genetic Programming (GP), Gene Expression Programming (GEP), and Support Vector Machine (SVM), Feed Forward Neural Network (FFNN), and Kernel Extreme Learning Machine (KELM)] were developed and applied for assessing the complex hydraulic and hydrologic phenomena efficiency. Real-time hydrologic forecasting (Yu et al., 2004), prediction of groundwater quality (Yang et al., 2017), hydraulic jump investigation in expanding channels (Roushangar et al., 2017), longitudinal dispersion coefficients computing in natural streams (Azamathulla and Wu, 2011), side weir discharge coefficient modeling (Azamathulla et al., 2017), monthly streamflow modeling (Zhu et al., 2018), predicting energy dissipation in culverts (Roushangar et al., 2019), and scour depth prediction around pier groups (Ebtehaj et al., 2018) are some of the examples. In general, the task of a machine learning algorithm can be described as follows: (1) with given a set of input variables and the associated output variable(s), (2) the objective is learning a functional relationship for the input-output variables set.

Due to the complexity of the flow resistance process, in the past few decades, accurate prediction of this parameter remains one of the most important tasks for scientific planning and management of water resources system. Due to the nonlinearity of the roughness coefficient in sewer pipes, the existing regression methods often don't show desired accuracy. Consequently, the application of many of these methods is limited to 
special cases of their development. This issue causes an uncertainty in the estimation of the roughness coefficient in channel pipes. With the advantages of easy implementation and high flexibility, artificial intelligence methods have been widely employed to address the complex hydraulic and hydrological prediction problems. Among artificial models, kernel based approaches such as KELM are relatively new important methods based on the different kernels type which are based on statistical learning theory initiated. Such models are capable of adapting itself to predict any variable of interest via sufficient inputs. The aim of this study was to assess the most significant variables in modeling the roughness coefficient of smooth and rough bed pipes using nonlinear approaches. Therefore, two Al models (i.e. FFNN, KELM) were applied to predict roughness coefficient in channels with smooth and rough beds and also investigate the best input models and effective parameters for each state. In this regard, the most important flow and sediment parameters were selected using Factorial Analysis (FA) method. FA method can be useful where there is a nonlinear relationship between inputs and output variables. In fact, it tries to recognize underlying factors, which explain the correlations pattern within a set of observed variables. Also, based on Tezcan et al. (2015), FA can be used for data reduction to select a small number of factors which explain most of the variance that is observed in a much larger number of manifest variables. Also, uncertainty analysis was performed to investigate the applied models dependability.

\section{Materials And Methods}

\section{The datasets}

In this study, to evaluate the roughness coefficient in circular channels, the experimental datasets of Ghani (1993) and May et al. (1989) were used. Ghani (1993) studied sediment transport and flow resistance in smooth and rough beds under part-full flow conditions. Two hundred and fifty four experiments on sediment transport of non-cohesive sediments in the non-deposition state were done in sewer pipes with diameters (D) of 154 , 305 , and $450 \mathrm{~mm}$ and a length of $20.5 \mathrm{~m}$. All the three sizes were used for smooth rigid beds and the $305 \mathrm{~mm}$ pipe also was used for a rough rigid bed. For transport experiments with a rough rigid boundary, two sizes of sand ( $d_{50}=0.5$ and $1.0 \mathrm{~mm}$ ), where $d_{50}$ is the median particle size were used to roughen the pipe artificially. The rigid boundary tests were done with a proportional flow depth of $0.15<y_{0} / D<0.80$, where $y_{0}$ is the depth of uniform flow. May et al. (1989) carried out thirty eight tests which were under part-full flow conditions on a pipe with diameter of $300 \mathrm{~mm}$ and length of 20 $\mathrm{m}$. The non-cohesive sediments with median diameter of $0.72 \mathrm{~mm}$, flow velocity in the range of $0.082<V<1.5 \mathrm{~m} / \mathrm{s}$, and specific gravity of $2.62 \mathrm{were}$ used during the experiments. Table 1 shows the ranges of some parameters used in these experiments. In this table $S_{0}, y / D, d_{50}, D, V, C v, k_{0}$, and $R e$ are slope of pipe, proportional flow depth, particles median diameter, pipes diameter, flow velocity, sediment concentration, clear-water equivalent sand roughness, and flow Reynolds number, respectively.

Table 1. Detail of various parameters from laboratory experiments used in this study.

\begin{tabular}{|c|c|c|c|c|c|c|}
\hline \multirow[t]{3}{*}{ Parameters } & \multicolumn{6}{|l|}{ Bed condition } \\
\hline & \multicolumn{4}{|l|}{ Smooth bed } & \multicolumn{2}{|l|}{ Rough bed } \\
\hline & Ghani & & & May et al & Ghani & \\
\hline $\mathrm{D}(\mathrm{mm})$ & 154 & 305 & 450 & 300 & $305(\mathrm{k} 0=0.53 \mathrm{~mm})$ & $305(\mathrm{k} 0=1.34 \mathrm{~mm})$ \\
\hline $\mathrm{V}(\mathrm{m} / \mathrm{s})$ & $0.24-0.862$ & $0.395-1.2$ & $0.502-1.2$ & $0.082-1.5$ & $0.411-1$ & $0.56-0.827$ \\
\hline$y / D$ & $0.153-0.756$ & $0.210-0.8$ & $0.50-0.75$ & $0.37-0.75$ & $0.18-0.77$ & $0.243-0.764$ \\
\hline $\mathrm{d}_{50}(\mathrm{~mm})$ & $0.93-5.7$ & $0.46-8.30$ & 0.72 & 0.72 & $0.97-8.30$ & $2.00-8.30$ \\
\hline $\mathrm{Cv}$ & $38-145$ & $1-1280$ & $2-37$ & $0.31-443$ & $1-923$ & 7- 403 \\
\hline $\operatorname{Re}\left(10^{5}\right)$ & $0.13-1.43$ & $0.87-2.7$ & $1.04-4.6$ & $0.75-6.5$ & $0.89-2.52$ & $0.98-2.1$ \\
\hline$S_{0}\left(10^{-2}\right)$ & $0.13-0.53$ & $0.06-0.53$ & $0.04-0.31$ & $0.14-0.56$ & $0.07-0.56$ & $0.13-0.56$ \\
\hline No. of data & 39 & 87 & 27 & 38 & 71 & 30 \\
\hline
\end{tabular}

\section{Artificial Intelligence (Al) techniques}

Two Al techniques including FFNN and Kernel extreme KELM were used to predict roughness coefficient in circular channels with smooth and rigid beds, whose brief description are provided below.

\section{- Feed Forward Neural Network (FFNN)}

The aim of ANN as a Meta model approach is to achieve a nonlinear relationship between inputs and output data series (Najafi et al., 2018). ANN is based on a collection of connected nodes called neurons, which are linked to certain of their neighbors with varying connective coefficients which show the connections strengths. FFNN is the most common algorithm of ANN, with having three layers of input, hidden and target. In this method the transfer of information is done in uni-direction: from the input nodes to the hidden and output nodes. Figure 1, shows a three-layer FFNN model. 
The hidden neuron sums up the input connections weights. For selecting the information which should be moved to the next neuron, in the hidden layer the weighted summation should be passed through an activation function (Tayfur, 2012).

\section{- Kemel extreme Learning Machine (KELM)}

Among data driven techniques, Kernel-based methods such as Kernel Extreme Learning Machine (KELM) are considered as relatively innovative and significant techniques in terms of various kernels types and the statistical learning theory. These models can adapt themselves for predicting any parameter of interest by adequate inputs. Furthermore, they can model non-linear decision boundaries, and numerous kernels exist in this regard. These methods are also objectively strong against overfitting, particularly in high-dimensional spaces. Nevertheless, proper selection of the kernel kind is the most essential step in the KELM method because of its direct effect on classification precision and training. There are various kernels functions such as linear, radial basis, and polynomial kernels.

Extreme Learning Machine (ELM) is an approach based on Single Layer Feed Forward Neural Network (SLFFNN). According to Huang et al. (2006), the SLFFNN is a straight framework where information weights linked to hidden neurons. The hidden layer biases are randomly opted, while the weights among the hidden nodes are resolved logically. According to Huang et al. (2006), in this method, execution is preferred and it is more compatible than previous learning methods, due to this fact that, unlike traditional methods that have many variables for setting up, in this method, much human intercession are not required for accomplishing ideal parameters in complex issues demonstrating. ELM design based on kernel function is known as Kernel Extreme Learning Machine (KELM). For more detail about KELM readers and researchers are referred to Huang et al. (2012).

For assessing the applied methods capability, three criteria were used including Determination Coefficient (NSE), Correlation Coefficient (R), and Root Mean Square Errors (RMSE) which can be formulated as:

$$
N S E=1-\frac{\sum_{i=1}^{N}\left(1_{o}-1_{p}\right)^{2}}{\sum_{i=1}^{N}\left(1_{0}-\overline{1_{p}}\right)^{2}}, R=\frac{\sum_{i=1}^{N}\left(1_{o}-\overline{1_{o}}\right) \times\left(1_{p}-\overline{1_{p}}\right)}{\sqrt{\sum_{i=1}^{N}\left(1_{0}-\overline{1_{0}}\right)^{2} \times\left(1_{p}-\overline{\bar{p}_{p}}\right)^{2}}}, \quad R M S E=\sqrt{\sum_{i=1}^{N D} \frac{\left(1_{o}-1_{p}\right)^{2}}{N D}}
$$

Where, ${ }^{,} l_{o}, l_{p}, \overline{l_{o}}, \overline{l_{p}}$, and ND are the observed, estimated, mean observed, mean estimated values, and number of experiments, respectively. Also, all input variables were scaled between $0-0.8$ in order to eliminate the input and output variables dimensions.

\section{Simulation and models development}

\section{Input variables}

Appropriate selection of input combination has significant impact on the accuracy of developed models. From the studies done by Ghani (1993), May et al. (1989) and Vongvisessomjai et al. (2010), the following variables can affect the flow resistance in pipe channels:

$V, D_{g r}, d_{50}, D, y$ or $R, F_{r m}, C_{v}$

where $D_{g r}$ is dimensionless particle number and $F_{r m}$ is Modified Froude number. The flow resistance in sediment transport sever pipes can be expressed as a function of different sets of input variables. In this study for selecting the most effective variables in modeling the roughness coefficient in circular channels the FA was used. Factorial Analysis is originated from experimental design to identify the interaction effects of several factors on a response variable (Tezcan et al., 2015). The results of FA are listed in Table 2 and Fig. 2(a). In this table variables Frand $A$ are flow Froude number and flow cross sectional area, respectively. Based on the results listed in Table 2, the most effective parameters were selected and several models were developed via combining these parameters as inputs for Al methods. Table 3 shows the considered models in assessing the roughness coefficient in circular channels with different bed conditions. According to the Fig. 2(b), two states were considered in models preparing. In the state 1, only hydraulic properties were used for Manning roughness coefficient modeling and in the state 2, the combination of both hydraulic and sediment properties were used as inputs. In this study, the Manning coefficient (n) was selected as output parameter. In the next steps, the most essential parameters in the prediction procedure were determined by utilizing sensitivity analysis, followed by employing Monte Carlo uncertainty analysis (UA) to evaluate the dependability of the applied models.

Table 2. Correlation matrix obtained from FA. 


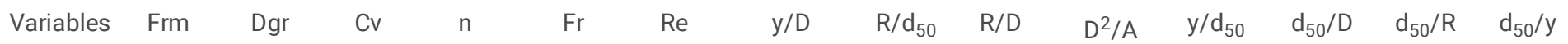
Smooth bed

\begin{tabular}{|c|c|c|c|c|c|c|c|c|c|c|c|c|c|c|}
\hline Frm & 1 & -0.710 & -0.277 & -0.453 & 0.046 & 0.721 & 0.299 & 0.762 & 0.288 & -0.272 & 0.716 & -0.738 & -0.736 & -0.717 \\
\hline Dgr & -0.710 & 1 & 0.539 & 0.342 & 0.325 & -0.348 & -0.291 & -0.698 & -0.257 & 0.161 & -0.664 & 0.883 & 0.841 & 0.810 \\
\hline $\mathrm{Cv}$ & -0.277 & 0.539 & 1 & 0.455 & 0.670 & -0.272 & -0.358 & -0.479 & -0.354 & 0.267 & -0.466 & 0.640 & 0.667 & 0.660 \\
\hline $\mathrm{n}$ & -0.453 & 0.342 & 0.455 & 1 & 0.483 & -0.613 & -0.423 & -0.420 & -0.467 & 0.570 & -0.408 & 0.437 & 0.572 & 0.592 \\
\hline $\mathrm{Fr}$ & & & & & 1 & -0.173 & -0.574 & -0.506 & -0.551 & 0.407 & -0.531 & 0.302 & 0.353 & 0.363 \\
\hline $\mathrm{Re}$ & & & & & & 1 & 0.515 & 0.774 & 0.517 & -0.491 & 0.769 & -0.521 & -0.565 & -0.561 \\
\hline$y / D$ & & & & & & & 1 & 0.576 & 0.972 & -0.852 & 0.637 & -0.227 & -0.447 & -0.504 \\
\hline$R / d_{50}$ & & & & & & & & 1 & 0.538 & -0.440 & 0.988 & -0.727 & -0.720 & -0.701 \\
\hline $\mathrm{R} / \mathrm{D}$ & & & & & & & & & 1 & -0.929 & 0.575 & -0.200 & -0.451 & -0.514 \\
\hline$D^{2} / A$ & & & & & & & & & & 1 & -0.460 & 0.141 & 0.409 & 0.472 \\
\hline$y / d_{50}$ & & & & & & & & & & & 1 & -0.690 & -0.687 & -0.670 \\
\hline $\mathrm{d}_{50} / \mathrm{D}$ & & & & & & & & & & & & 1 & 0.930 & 0.885 \\
\hline $\mathrm{d}_{50} / \mathrm{R}$ & & & & & & & & & & & & & 1 & 0.994 \\
\hline $\mathrm{d}_{50} / \mathrm{y}$ & & & & & & & & & & & & & & 1 \\
\hline
\end{tabular}

Rough bed

\begin{tabular}{|c|c|c|c|c|c|c|c|c|c|c|c|c|c|c|}
\hline Frm & 1 & -0.721 & -0.091 & -0.217 & 0.190 & 0.051 & -0.109 & 0.651 & -0.108 & 0.039 & 0.560 & -0.753 & -0.589 & -0.522 \\
\hline Dgr & -0.721 & 1 & 0.489 & 0.298 & 0.304 & 0.0530 & -0.270 & -0.763 & -0.242 & 0.234 & -0.724 & 0.975 & 0.864 & 0.803 \\
\hline $\mathrm{Cv}$ & -0.091 & 0.489 & 1 & 0.385 & 0.831 & -0.457 & -0.771 & -0.458 & -0.810 & 0.835 & -0.474 & 0.429 & 0.781 & 0.831 \\
\hline $\mathrm{n}$ & -0.417 & 0.298 & 0.385 & 1 & 0.384 & -0.742 & -0.452 & -0.333 & -0.489 & 0.471 & -0.334 & 0.199 & 0.402 & 0.433 \\
\hline $\mathrm{Fr}$ & & & & & 1 & -0.421 & -0.923 & -0.475 & -0.921 & 0.836 & -0.541 & 0.255 & 0.570 & 0.626 \\
\hline $\mathrm{Re}$ & & & & & & 1 & 0.646 & 0.147 & 0.708 & -0.741 & 0.176 & 0.046 & -0.354 & -0.431 \\
\hline$y / D$ & & & & & & & 1 & 0.456 & 0.985 & -0.891 & 0.536 & -0.211 & -0.573 & -0.641 \\
\hline $\mathrm{R} / \mathrm{d}_{50}$ & & & & & & & & 1 & 0.427 & -0.389 & 0.988 & -0.781 & -0.732 & -0.692 \\
\hline$R / D$ & & & & & & & & & 1 & -0.943 & 0.494 & -0.186 & -0.587 & -0.661 \\
\hline$D^{2} / A$ & & & & & & & & & & 1 & -0.433 & 0.181 & 0.616 & 0.691 \\
\hline $\mathrm{y} / \mathrm{d}_{50}$ & & & & & & & & & & & 1 & -0.737 & -0.708 & -0.674 \\
\hline$d_{50} / D$ & & & & & & & & & & & & 1 & 0.851 & 0.781 \\
\hline$d_{50} / R$ & & & & & & & & & & & & & 1 & 0.992 \\
\hline $\mathrm{d}_{50} / \mathrm{y}$ & & & & & & & & & & & & & & 1 \\
\hline
\end{tabular}

Table 3. The FFNN and KELM developed Models. 


\begin{tabular}{|c|c|c|c|}
\hline \multicolumn{4}{|c|}{ Modeling States } \\
\hline \multicolumn{2}{|c|}{ Hydraulic characteristics } & \multicolumn{2}{|c|}{ hydraulic and particle's characteristics } \\
\hline Model & Input(s) & Model & Input(s) \\
\hline$H(I)$ & $\operatorname{Re}$ & $\mathrm{HS}(\mathrm{I})$ & $\mathrm{F}_{\mathrm{rm}}, \mathrm{D}_{\mathrm{gr}}, \mathrm{d}_{50} / \mathrm{D}$ \\
\hline$H(I I)$ & $\mathrm{Re}, \mathrm{R} / \mathrm{D}$ & $\mathrm{HS}(\mathrm{II})$ & $\mathrm{F}_{\mathrm{rm}}, \mathrm{D}_{\mathrm{gr}}, \mathrm{d}_{50} / \mathrm{R}$ \\
\hline $\mathrm{H}(\mathrm{III})$ & $\mathrm{Fr}$ & $\mathrm{HS}(\mathrm{III})$ & $F_{r m}, D_{g r}, d_{50} / y$ \\
\hline \multirow[t]{3}{*}{$\mathrm{H}(\mathrm{IV})$} & $\mathrm{Fr}, \mathrm{R} / \mathrm{D}$ & HS(IV) & $\mathrm{F}_{\mathrm{rm}}, \mathrm{D}_{\mathrm{gr}}, \mathrm{Cv}$ \\
\hline & & $\mathrm{HS}(\mathrm{V})$ & $\mathrm{F}_{\mathrm{rm}}, \mathrm{D}_{\mathrm{gr}}, \mathrm{d}_{50} / \mathrm{R}, \mathrm{Cv}$ \\
\hline & & $\mathrm{HS}(\mathrm{VI})$ & $F_{r m}, D_{g r}, d_{50} / R, C v, D^{2} / A$ \\
\hline
\end{tabular}

\section{FFNN and KELM parameters setting}

For obtaining the desirable forecasting results, setting specific parameters of each artificial intelligent approach is required and their optimal values should be determined. For kernel based approaches designing, the appropriate kind of kernel function selection should be done. In this research, the roughness coefficient in smooth bed channel was predicted using different kernel types. In this regard, the model HS(VI) for the smooth bed was run via KELM and according to Fig. 3(a), the RBF kernel function [ in which $y$ is kernel parameter] was fined as the best kernel function. Figure 3(b) shows the RMSE via $y$ values for assessing the impact of RBF kernel parameter of $y$ on employed algorithm performance for testing set of model $\mathrm{HS}(\mathrm{VI})$ in the smooth bed channel. In this study, optimization of $\mathrm{y}$ was performed by a systematic grid search of the parameter using crossvalidation. On the other hand, in ANN modeling the network topology has direct effects on its computational complexity and generalization capability; therefore, the appropriate structure of ANN should be selected. Various networks were tested to determine the hidden layer node numbers. Different numbers of neurons (i.e. 2, 3, 5, and 7) in hidden layer were tested. Also, it was found that the tangent sigmoid and pure linear functions are suitable for the hidden and output node activation functions, respectively.

\section{Results And Discussion}

\section{The results obtained for the state 1 (the use of only hydraulic parameters)}

For assessing the impact of hydraulic parameters on roughness modeling, two models were defined using $y / D$ and $R e$ parameters. These two parameters were selected based on FA results listed in Table 2. Modeling based on hydraulic parameters can be useful in the cases where only data related to flow characteristics are available. Table 4 and Fig. 4 show the results of FFNN and KELM models. According to the results, it could be seen that when only hydraulic parameters were used for roughness coefficient modeling, the predicted and observed values led to poor agreement. For the state 1 , the model $\mathrm{H}(\mathrm{II})$ with input combination of Reand $y / D$ yielded in more accurate outcome and it seems that adding $y / D$ variable to inputs increased the models efficiency. As it could be seen from Table 4, the applied models represented more desirable results compared with rough channel. Also, the KELM model was slightly accurate than the FFNN model. However, according to the results, it could be induced that the models containing only hydraulic characteristics were not so accurate. The scatter plots of the KELM-best model for smooth and rough channels are shown in Fig. 4.

Table 4. The obtained results for roughness coefficient modeling in the state 1. 


\begin{tabular}{|c|c|c|c|c|c|c|c|}
\hline \multirow{3}{*}{$\begin{array}{l}\text { Models } \\
\text { Smooth bed }\end{array}$} & \multirow[t]{3}{*}{ Method } & \multicolumn{6}{|c|}{ Performance criteria } \\
\hline & & \multicolumn{3}{|c|}{ Train } & \multicolumn{3}{|c|}{ Test } \\
\hline & & $\mathrm{R}$ & NSE & RMSE & $\mathrm{R}$ & NSE & RMSE \\
\hline \multirow[t]{2}{*}{$\mathrm{H}(\mathrm{I})$} & FFNN & 0.887 & 0.808 & 0.059 & 0.879 & 0.767 & 0.069 \\
\hline & KELM & 0.898 & 0.816 & 0.061 & 0.890 & 0.769 & 0.072 \\
\hline \multirow[t]{2}{*}{$\mathrm{H}(\mathrm{II})$} & FFNN & 0.921 & 0.838 & 0.048 & 0.911 & 0.814 & 0.066 \\
\hline & KELM & 0.917 & 0.841 & 0.050 & 0.914 & 0.815 & 0.062 \\
\hline \multirow[t]{2}{*}{$\mathrm{H}(\mathrm{III})$} & FFNN & 0.466 & 0.384 & 0.110 & 0.402 & 0.315 & 0.118 \\
\hline & KELM & 0.481 & 0.391 & 0.101 & 0.422 & 0.311 & 0.111 \\
\hline \multirow[t]{2}{*}{$\mathrm{H}(\mathrm{IV})$} & FFNN & 0.919 & 0.817 & 0.060 & 0.912 & 0.788 & 0.067 \\
\hline & KELM & 0.921 & 0.823 & 0.057 & 0.901 & 0.792 & 0.064 \\
\hline \multicolumn{8}{|l|}{ Rough bed } \\
\hline \multirow[t]{2}{*}{$\mathrm{H}(\mathrm{I})$} & FFNN & 0.736 & 0.535 & 0.153 & 0.725 & 0.423 & 0.159 \\
\hline & KELM & 0.738 & 0.548 & 0.150 & 0.731 & 0.427 & 0.157 \\
\hline \multirow[t]{2}{*}{$\mathrm{H}(\mathrm{II})$} & FFNN & 0.869 & 0.737 & 0.078 & 0.859 & 0.708 & 0.098 \\
\hline & KELM & 0.866 & 0.739 & 0.076 & 0.859 & 0.711 & 0.094 \\
\hline \multirow[t]{2}{*}{$\mathrm{H}(\mathrm{III})$} & FFNN & 0.445 & 0.264 & 0.171 & 0.435 & 0.208 & 0.181 \\
\hline & KELM & 0.430 & 0.263 & 0.172 & 0.438 & 0.219 & 0.177 \\
\hline \multirow[t]{2}{*}{$\mathrm{H}(\mathrm{IV})$} & FFNN & 0.848 & 0.711 & 0.095 & 0.822 & 0.633 & 0.115 \\
\hline & KELM & 0.840 & 0.718 & 0.092 & 0.810 & 0.641 & 0.109 \\
\hline
\end{tabular}

The results obtained for the state 2 (the use of hydraulic and sediment parameters)

In this section for roughness coefficient predicting in circular channels with different bed condition, both hydraulic and sediment parameters were used for preparing the models. The results obtained for this state are presented in Table 5 and Fig. 5 . Based on the statistical performance criteria, it could be seen that for both smooth and rough bed channels the model $\mathrm{HS}(\mathrm{VI})$ with input parameters $C V, F_{r m}, D_{g n} d_{50} / R, D^{2} / A$ showed the most accurate results. It could be inferred that the use of $d_{50} / R$ and $D^{2} / A$ variables increased the models accuracy. By comparing the results of the states 1 and 2, it could be indicated that in roughness coefficient modeling, the use of both hydraulic and sediment parameters performed more successfully than when only hydraulic parameters were used. In state 2 , the first three models were developed without considering $C v$ as input and the last three models were developed considering $C v$ as input. From the results of these two sets, it seems that in modeling the roughness coefficient, using parameter $C v$ increased the models efficiency. Figure 5(a) displays the scatter plots of the KLEM-best model for two datasets. Also, for evaluating the impact of each independent parameter sensitivity analysis was performed for the model HS(VI). Therefore, in the HS(VI) model the input variables were omitted one by one and the KLEM model was rerun. The sensitivity analysis results for test series are presented in Fig. 5(c). The RMSE error criterion was used for showing the impact of each variable. It was found that variable $d_{50} / R$ in both circular channels was the most significant parameter.

Table 5. The obtained results for roughness coefficient modeling in the state 2. 


\begin{tabular}{|c|c|c|c|c|c|c|c|}
\hline \multirow[t]{3}{*}{ Models } & \multirow[t]{3}{*}{ Method } & \multicolumn{6}{|c|}{ Performance criteria } \\
\hline & & \multicolumn{3}{|c|}{ Train } & \multicolumn{3}{|c|}{ Test } \\
\hline & & $\mathrm{R}$ & NSE & RMSE & $\mathrm{R}$ & NSE & RMSE \\
\hline \multicolumn{8}{|c|}{ Smooth bed } \\
\hline \multirow[t]{2}{*}{$\mathrm{HS}(\mathrm{I})$} & FFNN & 0.909 & 0.819 & 0.055 & 0.896 & 0.758 & 0.075 \\
\hline & KELM & 0.923 & 0.843 & 0.053 & 0.923 & 0.766 & 0.073 \\
\hline \multirow[t]{2}{*}{$\mathrm{HS}(\mathrm{II})$} & FFNN & 0.957 & 0.902 & 0.043 & 0.958 & 0.877 & 0.055 \\
\hline & KELM & 0.961 & 0.919 & 0.040 & 0.974 & 0.887 & 0.053 \\
\hline \multirow[t]{2}{*}{ HS(III) } & FFNN & 0.960 & 0.909 & 0.046 & 0.932 & 0.801 & 0.060 \\
\hline & KELM & 0.965 & 0.922 & 0.043 & 0.944 & 0.826 & 0.058 \\
\hline \multirow[t]{2}{*}{ HS(IV) } & FFNN & 0.974 & 0.879 & 0.051 & 0.916 & 0.771 & 0.071 \\
\hline & KELM & 0.968 & 0.892 & 0.049 & 0.930 & 0.782 & 0.068 \\
\hline \multirow[t]{2}{*}{$\mathrm{HS}(\mathrm{V})$} & FFNN & 0.978 & 0.927 & 0.036 & 0.910 & 0.892 & 0.049 \\
\hline & KELM & 0.981 & 0.938 & 0.033 & 0.924 & 0.905 & 0.046 \\
\hline \multirow[t]{2}{*}{$\mathrm{HS}(\mathrm{VI})$} & FFNN & 0.982 & 0.944 & 0.030 & 0.922 & 0.911 & 0.042 \\
\hline & KELM & 0.984 & 0.948 & 0.028 & 0.931 & 0.918 & 0.039 \\
\hline \multicolumn{8}{|c|}{ Rough bed } \\
\hline \multirow[t]{2}{*}{$\mathrm{HS}(\mathrm{I})$} & FFNN & 0.718 & 0.566 & 0.147 & 0.651 & 0.374 & 0.169 \\
\hline & KELM & 0.728 & 0.577 & 0.141 & 0.671 & 0.378 & 0.167 \\
\hline \multirow[t]{2}{*}{$\mathrm{HS}(\mathrm{II})$} & FFNN & 0.937 & 0.814 & 0.064 & 0.847 & 0.766 & 0.079 \\
\hline & KELM & 0.940 & 0.830 & 0.056 & 0.861 & 0.774 & 0.071 \\
\hline \multirow[t]{2}{*}{ HS(III) } & FFNN & 0.934 & 0.910 & 0.047 & 0.890 & 0.751 & 0.082 \\
\hline & KELM & 0.939 & 0.923 & 0.045 & 0.901 & 0.770 & 0.075 \\
\hline \multirow[t]{2}{*}{ HS(IV) } & FFNN & 0.769 & 0.721 & 0.089 & 0.743 & 0.638 & 0.098 \\
\hline & KELM & 0.759 & 0.732 & 0.084 & 0.741 & 0.643 & 0.092 \\
\hline \multirow[t]{2}{*}{$\mathrm{HS}(\mathrm{V})$} & FFNN & 0.966 & 0.925 & 0.044 & 0.889 & 0.818 & 0.063 \\
\hline & KELM & 0.966 & 0.928 & 0.043 & 0.902 & 0.821 & 0.059 \\
\hline \multirow[t]{2}{*}{$\mathrm{HS}(\mathrm{VI})$} & FFNN & 0.972 & 0.932 & 0.040 & 0.861 & 0.828 & 0.057 \\
\hline & KELM & 0.970 & 0.936 & 0.038 & 0.857 & 0.848 & 0.053 \\
\hline
\end{tabular}

\section{Combined data}

In this section, the performance of applied methods was assessed for a wider range of data. In this regard, applied datasets were mixed; then, two developed models in the state 2 were selected and reanalyzed for the new datasets. The obtained results are listed in Fig. 6 . From the results, it was found that the model $\mathrm{HS}(\mathrm{VI})$ led to better prediction than the model $\mathrm{HS}(\mathrm{V})$ and using parameter $D^{2} / A$ caused an improvement in models' efficiency. However, comparison between the results of Tables 4 and 5 and Fig. 6 showed that FFNN and KELM models for this state lead to undesired accuracy and separate datasets yielded better predictions. However it should be noted that the mixed datasets results is capable to cover wider range of data and in this case roughness coefficient can be studied without regarding the pipe bed condition (i.e. smooth or rough states).

\section{The results of uncertainty analysis}

The uncertainty of the best KELM model was determined by the uncertainty analysis (UA). In the current study, the Monte Carlo UA method was utilized as well. In the UA method, two elements are applied to measure the robustness and evaluate model uncertainty. The first one is the percentage of the investigated outputs within the range of 95PPU, and the next one represents the average distance between the lower $\left(X_{L}\right)$ and upper $\left(X_{U}\right)$ uncertainty bands (Noori et al., 2015). Accordingly, the intended model needs to be run several times (1000 times in this study), and the experimental cumulative distribution probability of the models should be determined as well. The lower and upper bands are regarded as the probabilities of 97.5 and $2.5 \%$ for the cumulative distribution, respectively. Two important indices should be taken into account at the appropriate 
confidence level. First, the 95PPU band brackets most observations. In addition, the average distance between the upper and lower parts of the 95PPU (d-Factor) should be smaller than the standard deviation of the observed data (Abbaspour et al., 2007). The indicated indices were used for estimating input uncertainties. According to Abbaspour et al. (2007), the average width of the confidence interval band can be computed by Eq. (2):

$$
\text { d - factore }=\frac{\overline{c x}}{\sigma x}
$$

where $\sigma \mathrm{x}$ and $\bar{c} x$ are the observed data standard deviation and the average width

of confidence band, respectively. The 95PPU can be calculated as:

$$
\text { Bracketed by } 95 \mathrm{PPU}=\frac{1}{k} \operatorname{Cont}\left(j \mid X_{L}<X_{r e g}<X_{U}\right.
$$

where 95PPU, $k$, and $\mathrm{X}_{\text {reg }}$ represent the predicted uncertainty of $95 \%$, the observed data number, and the currently registered data, respectively. Figure 7 presents the obtained results for the UA. According to the d-Factor values and 95\% PPU, for both smooth and rough bed channels the predicted and observed values were within the $95 \%$ PPU band in most cases. Additionally, the findings revealed that the rate of $d$-Factors for training and testing datasets was lower compared to the standard deviation of the observed data. Therefore, based on the results, it could be induced that the roughness coefficient modeling via KELM model resulted in the allowable uncertainty level.

\section{Conclusions}

An accurate prediction of the roughness coefficient in channels with different bed condition is an important issue due to its impact on such structures performances. This study aimed to assess the efficiency of the FFNN and KELM methods in roughness coefficient modeling in smooth and rough bed circular channels. In the model developing process, first of all, the most effective variables were determined via FA, then, considering the various combinations of hydraulic and sediment parameters different models were developed. The results indicated that the models which took advantages of both hydraulic and sediment characteristics performed much better than developed models based on only hydraulic variables. The results showed that the model $\mathrm{HS}(\mathrm{VI})$ with $C v, F_{r m}, D_{g n} d_{50} / R, D^{2} / A$ variables had superior prediction ability in roughness coefficient modeling. Also, the use of $y / D, C v$ and $d_{50} / R$ variables increased the models accuracy. It was observed that the obtained RMSE values for smooth bed channel were less than those obtained for rough bed channel. Also, the KELM method was more accurate than FFNN method. The results of sensitivity analysis indicated that the impact of variable $d_{50} / R$ on obtaining a model with higher accuracy was more than other used parameters. Moreover, the dependability of the superior applied models was assessed through UA, and it was revealed that the KELM model possessed an acceptable uncertainty degree in the Manning roughness coefficient modeling in channels with different bed condition.

\section{Declarations}

\section{Author Contribution}

Roghayeh Ghasempour: Conceptualization, Supervision, Methodology, Review \& Editing. Kiyoumars Roushangar: Project administration, Investigation, Data Curation, Methodology, Writing.

HaziMohammad Azamathulla: Project administration, Investigation, Data Curation, Methodology.

Farhad Alizadeh: Formal analysis, Project administration, Data analysis, Review \& Editing.

Funding The authors did not receive support from any organization for the submitted work.

Availability of Data and Material Some or all data, models, or code that support the findings of this study are available from the corresponding author upon reasonable request.

\section{Ethics Approval}

Not applicable.

\section{Consent to Participate}

Not applicable.

\section{Consent for Publication}

Not applicable.

\section{Conflict of Interest}

The authors declare no conflicts of interest/competing interests. 


\section{References}

1. Abbaspour K.C., Yang J., Maximov I., Siber R., Bogner K., Mieleitner J., Zobrist J. and Srinivasan R. 2007 Modelling hydrology and water quality in the prealpine/alpine Thur watershed using SWAT. Journal of Hydrology, 333(2), 413-430.

2. Ackers P. 1961 The hydraulic resistance of drainage conduits. Proc. Institution of Civil Engineers, 19, 307-336.

3. Ackers P., Crickmore M. J, and Holmes D. W. 1964 Effects of use on the hydraulic resistance of drainage conduits. Proc. Institution of Civil Engineers, 28, 339-360.

4. Ashley R. M. and Crabtree R. W. 1992 Sediment origins, deposition, and build-up in combined sewers systems. Water Science and Technology, 25(8), 1-12.

5. Azamathulla H. M., Haghiabi A. H. and Parsaie A. 2017 Prediction of side weir discharge coefficient by support vector machine technique. Water Science and Technology: Water Supply, 16(4), 1002-1016.

6. Azamathulla H. M., Wu F. C. 2011 Support vector machine approach for longitudinal dispersion coefficients in natural streams. Applied Soft Computing, 11, 2902-2905.

7. Ebtehaj I., Bonakdari H., Moradi F., Gharabaghi B. and Khozani Z. S. 2018 An integrated framework of Extreme Learning Machines for predicting scour at pile groups in clear water condition. Coastal Engineering, 135, 1-15.

8. Einstein H. A. and Barbarossa N. L. 1952 River Channel Roughness. Trans. ASCE, Vol. 117.

9. Ghani A. A. 1993 Sediment transport in sewers (Ph.D thesis). Department of Civil Engineering, University of Newcastle Upon Tyne, England.

10. Henderson R. J. 1984 A guide to hydraulic roughness in sewers. WRc Engineering, Swindon, England, External Report E. 131E.

11. Huang G. B., Zhou H., Ding X. and Zhang R. 2012 Extreme Learning Machine for Regression and Multiclass Classification. IEEE Transactions on Systems, Man, and Cybernetics, Part B (Cybernetics), 42(2), 513-529.

12. Huang G. B., Zhu Q. Y. and Siew C. K. 2006 Extreme learning machine: theory and applications. Neurocomputing, 70(1-3), 489-501.

13. Kleijwegt R. A. 1992 Sewer sediment models and basic knowledge. Water Science and Technology, 25(8), $123-130$.

14. May R. W. P., Brown P. M., Hare G. R. and Jones K. D. 1989 Self-cleansing conditions for sewers carrying sediment (Report SR 221). Hydraulics Research Ltd., Wallingford, England.

15. May R.W.P. 2003 Preventing sediment deposition in inverted sewer siphons. Journal of hydraulic Engineering, 129(4), $283-290$.

16. Meyer Peter E. and Mueller R. 1948 Formulas for Bed Load Transport. Hyd. Research, 2nd meeting, No. 2.

17. Najafi B., Faizollahzadeh Ardabili S., Shamshirband S., Chau K. W. and Rabczuk T. 2018 Application of ANNs, ANFIS and RSM to estimating and optimizing the parameters that affect the yield and cost of biodiesel production. Engineering Applications of Computational Fluid Mechanics, 12(1), 611-624.

18. Nalluri C., Ota J. J. 2000 Non-cohesive sediment transport in clean sewers and with small mobile beds. In Building Partnerships (pp.1-11).

19. Noori R., Deng Z., Kiaghadi A., Kachoosangi F.T. 2015 How reliable are ann, anfis, and svm techniques for predicting longitudinal dispersion coefficient in natural rivers?. Hydraulic Engineering, 142(1), 04015039.

20. Novak P. and Nalluri C. 1972 A study into the correlation of sediment motion.. in pipe- and open channel flow. Proc. 2nd. Intern. Conf. on the Hydraulic Transport of Solids in Pipes, Hydrotransport, 2(4), 33-51.

21. Ojos S. I. A. 1978 Study of incipient motions and sediment transport over fixed beds (Ph.D thesis). University of Newcastle upon Tyne.

22. Ota J. J., Nalluri C. 2003 Urban storm sewer design: Approach in consideration of sediments. Journal of Hydraulic Engineering, 129(4), 291-297.

23. Richardson E. V. and Simons D. B. 1967 Resistance to Flow in Sand Channels. Proc. 12th Congress IAHR, Vol. 1.

24. Roushangar K., Matin G.N., Ghasempour R. and Saghebian S.M. 2019 Evaluation of the effective parameters on energy losses of rectangular and circular culverts via kernel-based approaches. Journal of Hydroinformatics, 21(6), 1014-1029.

25. Roushangar K., Valizadeh R. and Ghasempour R. 2017 Estimation of hydraulic jump characteristics of channels with sudden diverging side walls via SVM. Water Science and Technology, 76(7), 1614-1628.

26. Tayfur G. 2012 Soft computing methods in water resources engineering: Artificial neural networks, fuzzy logic, and genetic algorithm. WIT Press, Southampton, UK.

27. Tezcan U. U., Ates F., Erginel N., Ozcan O. and Oduncu E. 2015 Adsorption of disperse range 30 dye onto activated carbon derived from Holm Oak (Quercus llex) acorns: A 3k factorial design and analysis. Journal of environmental management, 155, 89-96.

28. Van der Mark C. F., Blom A. and Hulscher S. J. 2008 Quantification of variability in bedform geometry. Journal of Geophysical research, 113, 311.

29. Vongvisessomjai N., Tingsanchali T. and Babel M. S. 2010 Non-deposition design criteria for sewers with part-full flow. Urban Water Journal, 7(1), 61-77.

30. Yang Q., Zhang J., Hou Z., Lei X., Tai W. Chen, W. and Chen T. 2017 Shallow groundwater quality assessment: use of the improved Nemerow pollution index, wavelet transform and neural networks. Journal of Hydroinformatics, 19(5), 784-794.

31. Yang S. Q., Tan S. K. and Lim S. Y. 2005 Flow resistance and bedform geometry in a wide alluvial channel. Water Resource Research, 41(9), 1-8.

Page 10/14 
32. Yu X., Liong S.Y., Babovic V. 2004 EC-SVM approach for real-time hydrologic forecasting. Journal of Hydroinformatics, 6(3), $209-223$.

33. Zhu S., Luo X., Xu Z. and Ye L. 2018 Seasonal streamflow forecasts using mixture-kernel GPR and advanced methods of input variable selection. Hydrology Research, 50(1), 200-214.

\section{Figures}

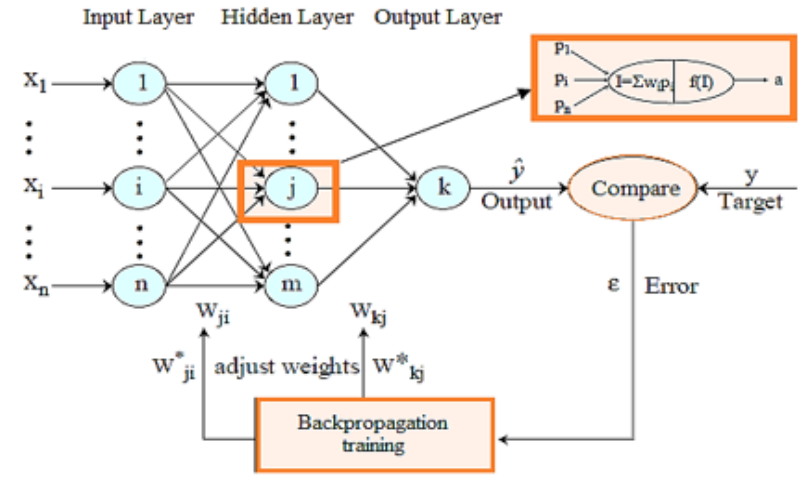

\section{Figure 1}

Typical three layered FFNNs with a backpropagation training algorithm. 

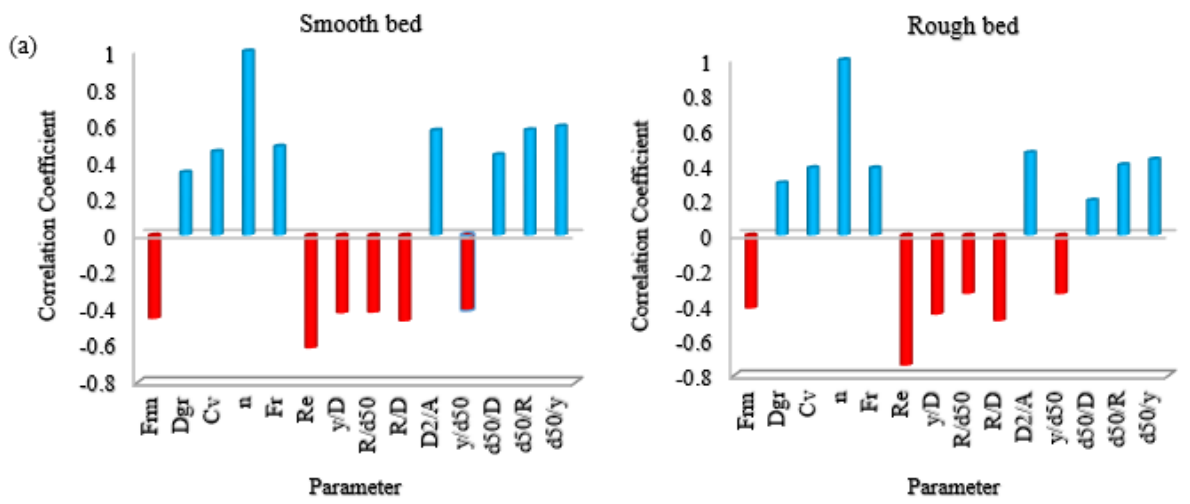

(b)

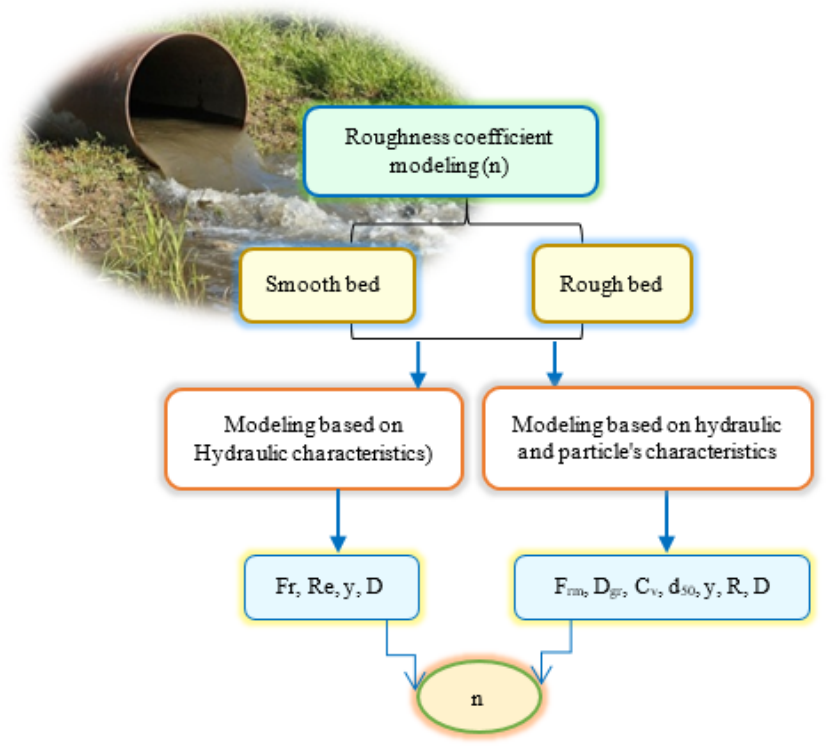

\section{Figure 2}

(a): Correlation between roughness coefficient and other parameters and (b): the schematic view of different states considered in the study.

(a)

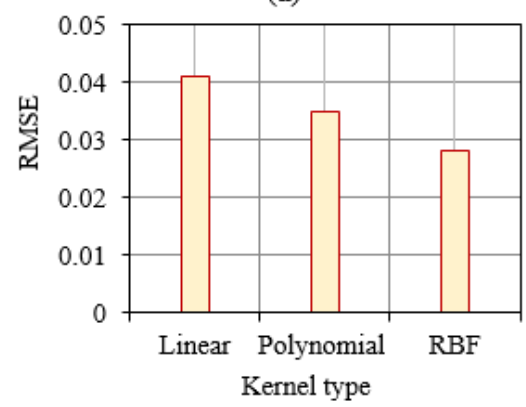

(b) RMSE

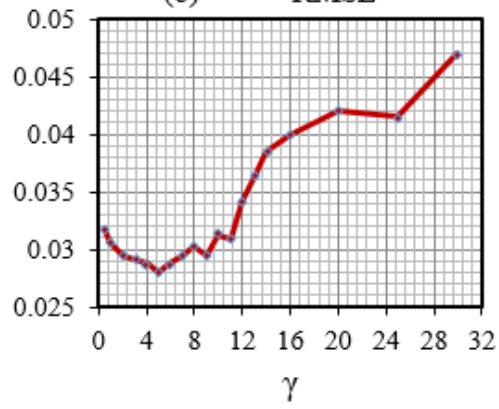

\section{Figure 3}

The RMSE statistics parameter via (a): KELM kernels function types and (b): $y$ values to find KELM optimums of testing set for model HS(VI). 


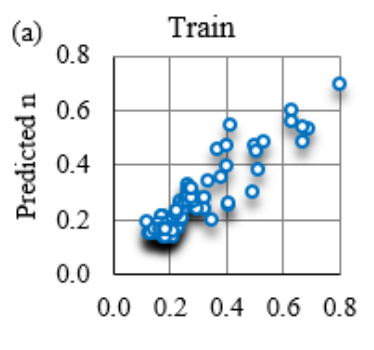

Observed n
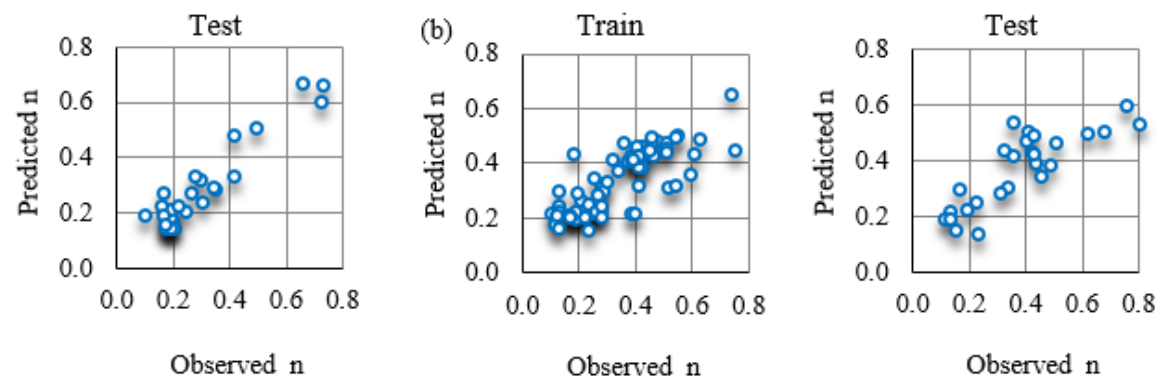

Figure 4

Comparison of observed and predicted roughness coefficient for the model H(II) of KELM method; (a): smooth bed and (b): rough bed channels.
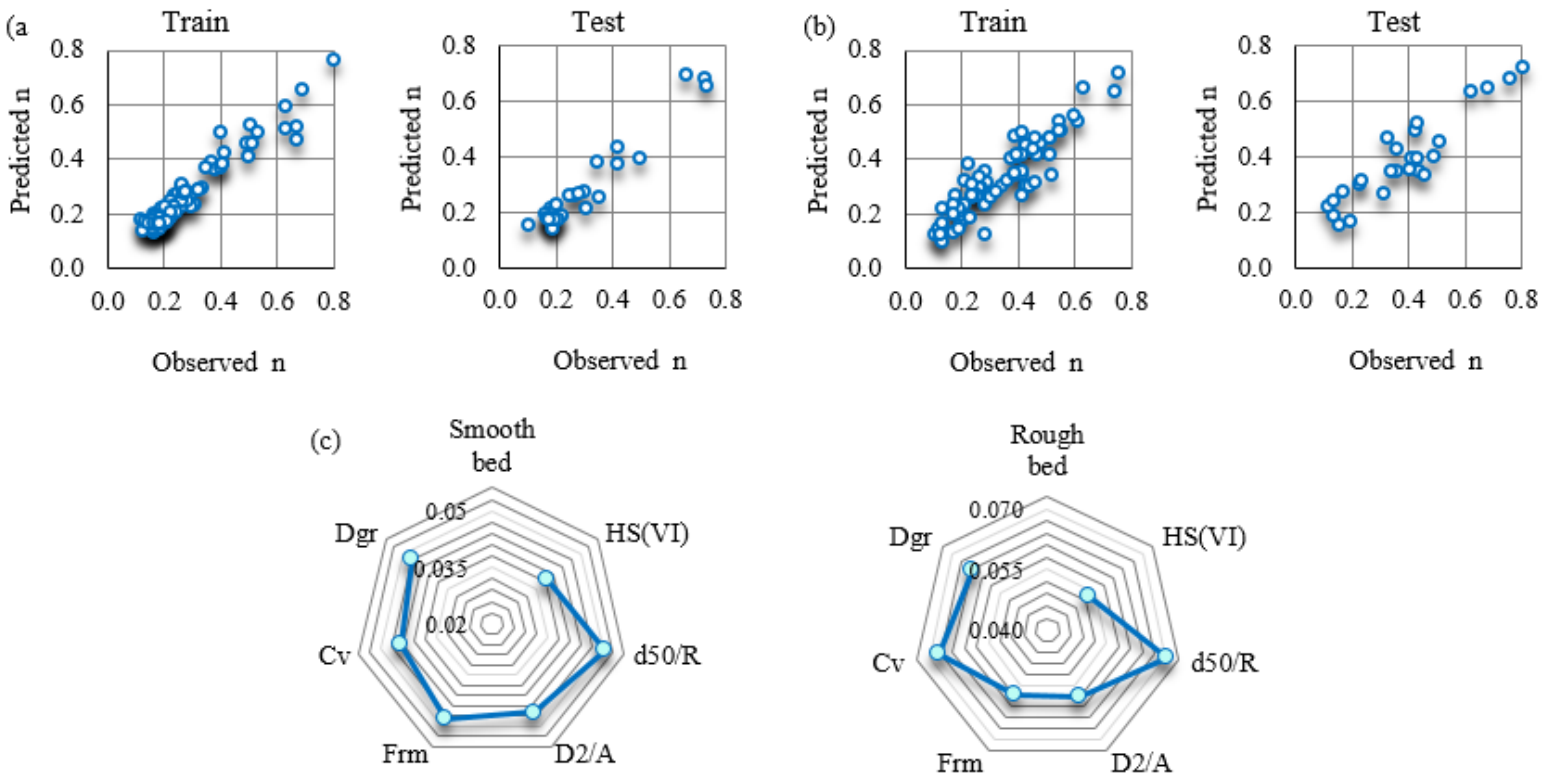

Figure 5

Comparison of observed and predicted roughness coefficient for the model HS(VI) of KELM method; (a): smooth bed and (b): rough bed channels, and (c): the RMSE statistical parameter obtained from sensitivity analysis. 

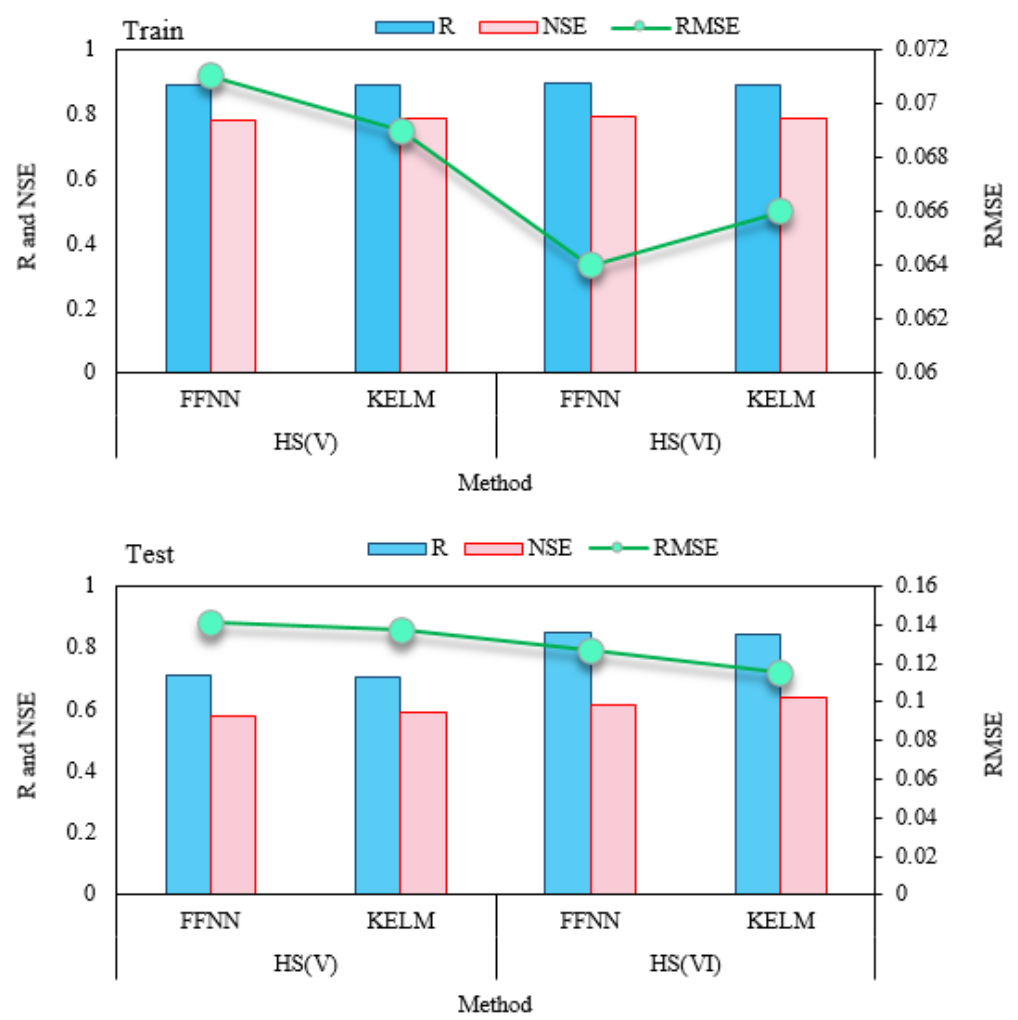

Figure 6

Statistical parameters of the FFNN and KELM models for mixed data.
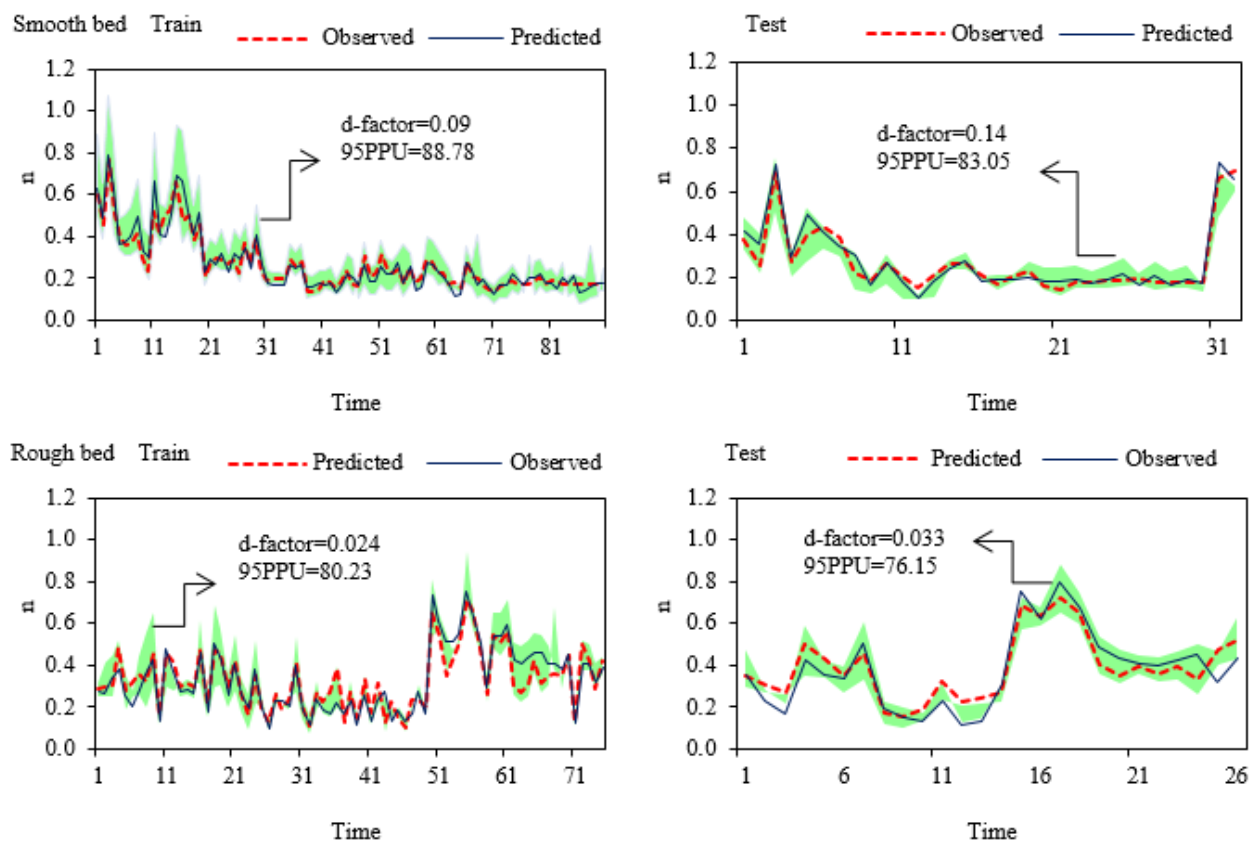

Figure 7

Uncertainty analysis for the best model of the KELM method. 